\title{
Continuity and Change in Interorganizational Project Practices: The Dutch Shipbuilding Industry, 1950-2010
}

\author{
Roland Levering \\ Department of Organization Studies - Center \\ for Innovation Research \\ Tilburg University, the Netherlands \\ E-mail: r.c.levering@uvt.nl
}

Niels Noorderhaven

Department of Organization \& Strategy -

Center for Innovation Research

Tilburg University, the Netherlands

E-mail: n.g.noorderhaven@uvt.nl

\author{
Rik Ligthart \\ Department of Organization Studies - Center \\ for Innovation Research \\ Tilburg University, the Netherlands \\ E-mail: h.d.ligthart@uvt.nl \\ Leon Oerlemans \\ Department of Organization Studies - Center \\ for Innovation Research \\ Tilburg University, the Netherlands \\ Graduate School of Technology Management \\ University of Pretoria, South Africa \\ E-mail: I.a.g.oerlemans@uvt.nl
}

\begin{abstract}
The Dutch shipbuilding industry has a longstanding tradition in project-based production. Recently, industry actors have acknowledged a serious misfit between interorganizational project practices, defined as behaviors related to collaboration, and interorganizational project demands, defined as environmental conditions. This misfit leads to a weaker competitive position due to higher communication and production costs, and longer production times. However, the causes of this misfit remain unclear. Among project researchers there is a growing awareness that history has a major influence on contemporary practices in interorganizational projects, suggesting that some of the causes of the present-day misfit may be rooted in the past. This paper studies historical developments of interorganizational project practices in Dutch shipbuilding projects, in order to understand to what extent contemporary misfit in project practices is rooted in the past and results from path dependencies and lock-ins. We answer the following research question: How did interorganizational project practices and demands in the Dutch shipbuilding industry develop between 1950 and 2010 and to what extent do these developments help us understand the current misfit between project practices and demands? Our results show that a web of selfreinforcing mechanisms at least partially explains the current misfit in the Dutch shipbuilding industry. This paper answers to the conceptual call by Sydow et al. (2009) and supplements path dependence literature by showing that self-reinforcing mechanisms causing path dependence can be separated analytically, but are intertwined empirically.
\end{abstract}

Keywords: Project history, Interorganizational projects, Path dependency 


\title{
Continuity and Change in Interorganizational Project Practices: The Dutch Shipbuilding Industry, 1950-2010
}

\begin{abstract}
The Dutch shipbuilding industry has a longstanding tradition in project-based production. Recently, industry actors have acknowledged a serious misfit between interorganizational project practices, defined as behaviors related to collaboration, and interorganizational project demands, defined as environmental conditions. This misfit leads to a weaker competitive position due to higher communication and production costs, and longer production times. However, the causes of this misfit remain unclear. Among project researchers there is a growing awareness that history has a major influence on contemporary practices in interorganizational projects, suggesting that some of the causes of the present-day misfit may be rooted in the past. This paper studies historical developments of interorganizational project practices in Dutch shipbuilding projects, in order to understand to what extent contemporary misfit in project practices is rooted in the past and results from path dependencies and lock-ins. We answer the following research question: How did interorganizational project practices and demands in the Dutch shipbuilding industry develop between 1950 and 2010 and to what extent do these developments help us understand the current misfit between project practices and demands? Our results show that a web of selfreinforcing mechanisms at least partially explains the current misfit in the Dutch shipbuilding industry. This paper answers to the conceptual call by Sydow et al. (2009) and supplements path dependence literature by showing that self-reinforcing mechanisms causing path dependence can be separated analytically, but are intertwined empirically.
\end{abstract}

Keywords: Project history, Interorganizational projects, Path dependency 


\section{Introduction}

Interorganizational projects are an increasingly prevalent phenomenon (Bakker et al., 2011). Besides in the shipbuilding industry (Ahola, Laitinen, Kujala, \& Wikström, 2008) they can be found in different industries such as film making (Bechky, 2006) and theatre production (Goodman \& Goodman, 1976). Jones and Lichtenstein (2008) set the interorganizational project apart from other forms of interorganizational coordination by identifying the temporary nature as its key distinction. This temporary nature is assumed to impact on the processes, practices, and behaviors taking place in these projects. We define interorganizational projects (henceforth IO projects) as "two or more organizational actors from distinct organizations working jointly to create a tangible product/service in a limited period of time." (Jones \& Lichtenstein, 2008, p. 234). Interorganizational collaboration is often characterized by slow and painful processes and leads to mixed results, a phenomenon Huxham (2003) terms 'collaboration inertia'. Dille and Soderlund (2011) adhere to this viewpoint, stating that interorganizational projects "are usually plagued by challenges in terms of both cooperation and coordination and replete with delays and collaborative failures." (p. 481). Several studies show that such frictions even lead to failures (Polidoro, Ahuja \& Mitchell, 2011).

In contemporary Dutch shipbuilding industry, shipyards, subcontractors, and suppliers collaborate in 10 projects to produce complex vessels. Recently, industry actors acknowledged that contemporary interorganizational practices (e.g. with regard to communication and knowledge sharing) in Dutch shipbuilding projects are problematic and do not fit well with contemporary interorganizational project demands (related to increased specialization and outsourcing). We define $1 O$ project practices as project participants' routine actions for coordinating activities and relations (Kostova \& Roth, 2002; March \& Simon, 1958; Windeler \& Sydow, 2001), whereas project demands are seen as environmental conditions (cf. Wiersema \& Bantel, 1993) that render certain collaboration practices more or less effective. Environmental, here, refers to the environment in which the project is embedded, for instance competition and technological development. When IO project practices do not match with project demands (i.e., environmental conditions), misfit occurs, and efficiency might suffer (Tushman \& Nadler, 1978). To deal with problems caused by the experienced misfit, in 2008 two of the leading Dutch shipyards, together with a number of their subcontractors, started a large-scale program to improve the quality of interorganizational project practices. The program is part of a larger maritime innovation agenda which is supported by the Dutch ministry of economic affairs. The participants formulated their problems in their initial program report as follows:

"Specialization has led to fragmentation. Conflicting interests are a logical consequence and not infrequently impede collaboration. (...) But also assembling the necessary amount of knowledge, information and different disciplines, along with the fact that more than 70 per cent of the ship construction is delivered from outside the shipyard within a 
very tight schedule can sometimes cause great problems." (Integrative Collaboration report, 2008).

According to the program director of the improvement program, problems encountered within IO shipbuilding projects due to misfit are for instance: information exchange difficulties between organizations involved in the project, subjective (sub-optimal) purchasing decisions in buyersupplier relationships, and a failure to capitalize on available expertise in the pre-project phase. These problems result in higher communication, learning and production costs, and longer delivery times of shipbuilding projects and as such corrode the competitive position of the Dutch shipbuilding industry on the global shipbuilding market. The participants in the maritime improvement program in The Netherlands responded to the experienced problems by setting goals that should make the industry more competitive and decrease the misfit between the project practices and demands. Under the umbrella of the overall goal of improved collaboration, the program aims at, among others, reducing failure costs, increasing employee motivation, and improving knowledge storage and exchange. The participants in the program state that: "an improvement in collaboration is needed in order to overcome the separation between the different phases in the construction process, between disciplines, and for joint risk management towards the customer"1.

However, the causes of the misfit between IO project practices and demands remain unclear. Recent work in the field of project management proposes that current project practices and misfits should be understood in the context of historical developments (e.g., Engwall, 2003). Still, research on collaboration in 10 projects typically does not put observed contemporary practices and demands in a historical perspective, thus neglecting the possibility that project practices may be reproduced from one temporary inter-organizational project to another (Windeler \& Sydow, 2001), rather than reflecting adaptation to present circumstances and demands. If the historical dimension is left out of consideration, the implicit assumption is that $1 O$ project practices are only and immediately influenced by the current set of demands. This type of analysis neglects organizational inertia and path dependency (Sydow, Schreyögg, \& Koch, 2009). Motivated by a strong belief in the importance of project history, scholars have recently called for the development of a history of projects (e.g., Jones \& Khanna, 2006; Usdiken \& Kieser, 2004). Responding to this call, we adopt a historical perspective in our examination of 10 project practices in Dutch shipbuilding. A historical perspective, as propagated in the 'historic turn' in organization studies (Clark \& Rowlinson, 2004), enables researchers to capture how project practices are over time influenced by changing forces in the environment, which is considered essential as environments, firm strategies, and organizations themselves change (Jones \& Khanna, 2006). Also, it allows for the exploration of path-dependent aspects of project practices. The main thrust of the present paper is that the misfit between contemporary $1 \mathrm{O}$ project practices and demands in the Dutch shipbuilding industry is in part caused by historical conditions. IO

\footnotetext{
${ }^{1}$ Taken from the improvement program website, www.integraalsamenwerken.nl, 2012
} 
project practices would follow external project demands in the absence of historically determined path-dependency. Currently, some of the 10 project practices are in a misfit with the contemporary 10 project demands. For some practices we observe a lock-in, i.e., these practices have remained unaltered in spite of changes in project demands. Other practices did change, however, their adaptation to changing project demands followed a path-dependent process, in which possible alternatives that might have led to better fit were neglected.

\section{Aim and outline}

The goal of this paper is to examine how the observed misfit between 10 project practices and demands in contemporary Dutch shipbuilding projects are partly rooted in the past and consequently are the result of path dependencies and lock-ins. We answer the following research question: How did interorganizational project practices and demands in the Dutch shipbuilding industry develop between 1950 and 2010 and to what extent do these developments help us understand the current misfit between project practices and demands? Our study on historical interorganizational collaboration aims to shed light on the historical roots of contemporary project practices. By doing so, it aids project managers and practitioners in better understanding the relationship between their project surroundings and their interior project management processes. Such an understanding will be supportive for managerial action since project management remains a difficult effort with many projects failing to meet their objectives within time and budget (White \& Fortune, 2002). Answering to the call by Sydow et al. (2009), this paper supplements path dependence literature by applying its insights to an interorganizational collaboration context. We show that although self-reinforcing mechanisms causing path dependence can be separated analytically, in the context of our study these mechanisms are strongly intertwined.

The paper is structured as follows. In the theoretical section contingency theory is used to theorize the notion of fit between 10 project practices and demands. We complement the idea of fit, or, in our study, of misfit, with a historical view on lock-in effects and path dependency. In the empirical part of the paper we first describe the major developments in project demands on interorganizational collaboration between shipyards and subcontractors in Dutch shipbuilding during the past half century. After that, a description of changes in 10 project practices is presented in order to arrive at the main aim of the paper: understanding how lock-in effects are partly at work and can explain the current misfit between 10 practices and demands. For reasons of clarity, it should be noted that we do assume neither a fit nor a misfit in the Dutch shipbuilding industry in earlier times. Rather, the focus lies at understanding the current misfit. For that purpose, the developments in 10 project demands and practices are described after which misfits due to path dependency and lock-in effects can be identified. 


\section{Theoretical background: misfit, path dependence and lock-in}

The concept of fit is central to structural contingency theory and has received much scholarly attention (Siggelkow, 2001; Van de Ven, 1979). A basic assumption of structural contingency is that the internal organization, in order to be effective, must be aligned with its external environment (Drazin \& Van de Ven, 1985). Elements of the external environment include for example the level of competition and (technological) uncertainty (Eskerod, 1996; Jensen, Johansson, \& Löfström, 2006). The fit between internal organization and environment is usually described as external fit (Lawrence \& Lorsch, 1967). The present study concentrates on the (mis)fit between interorganizational project practices and the environment in which the project is embedded. If these practices do not match with environmental demands, problematic misfit occurs, and for example efficiency suffers (Tushman \& Nadler, 1978). Practices, including project practices, tend to have a taken-for-granted, institutionalized nature (Nelson \& Winter, 1982), which somewhat contradicts the view of $\mathrm{IO}$ projects as "a panacea against strategic persistence and structural inertia" (Sydow, 2009, p. 123). With regard to the environment of IO projects, it is worth noting that it is rarely stable (Duncan, 1972; Aldrich \& Pfeffer, 1976). This implies that over time an initial fit can become a misfit when environmental demands change and practices do not change accordingly (Gresov, 1989). Such fit-destroying environmental changes should induce project participants to change their practices to bring them in line again with the new environmental demands (Siggelkow, 2001). However, attempts of organizations to restructure practices to regain fit are not always effective (Mintzberg, 1978; Tushman \& Romanelli, 1985) so that misfit remains.

In trying to explain misfit, scholars increasingly point to the role of history (e.g., Sydow et al., 2009). If we assume that history at least partially influences current misfit, the path dependence concept appears a fruitful theoretical starting point (Schreyögg \& Sydow, 2011). Applying only a contingency perspective - from which the concept of fit originates - would be of limited value. Contingency theory has been criticized for being inherently static and a-historical, failing to take into account the effects of past organizational behavior on current practices and (mis)fit (Donaldson, 1987; Shenhar \& Dvir, 1996). Path dependence explicitly considers imprinting effects of the past on current behavior (Beckman \& Burton, 2008). Path dependence is a broad concept indicating that prior organizational actions or behavior closes down possible future paths of actions or behaviors (Jones \& Khanna, 2006). Path dependence is related to - but not the same as - other theoretical mechanisms that connect the past and the present and which state that 'history matters' (Nooteboom, 1997), like institutional persistence and structural inertia. ${ }^{2}$ Institutions for example have a tendency to evolve incrementally rather than radically, making it more likely that today's practices are very similar to yesterday's practices (Scott, 1995). Institutionalized practices consist of rules and resources that are produced and reproduced over

\footnotetext{
${ }^{2}$ For a more detailed overview of how path dependence differs from other 'history matters' notions, see Vergne and Durand (2010, p. 742)
} 
time (Dille \& Söderlund, 2011), shaping how organization members perceive the environment and guiding organizational behavior (Phillips, Lawrence, \& Hardy, 2000).

Though the concept of path dependence is quoted frequently, its meaning and logic often remain vague and ambiguous (Schreyögg, Sydow, \& Holtmann, 2011). To deal with this issue, any theoretical or empirical contribution to the path dependence literature should start with a proper definition of the concept (Vergne \& Durand, 2010). In order to separate path dependence from other 'history matters' notions, we use a rather narrow definition, one that makes a distinction between the outcome of path dependence (so-called lock-ins) and the mechanism realizing that outcome (self-reinforcement). We define path dependence of practices as a process causing practices to be self-reinforcing, resulting in lock-in in the absence of exogenous shocks (based on Vergne \& Durand, 2010). This definition is in line with Sydow and colleagues (2009), who claim that path dependence is first of all a process consisting of three developmental phases. In phase 1 - the Pre-formation phase - the range of practices from which participants can choose is broad. However, at so-called 'critical junctures' (Collier \& Collier, 1991), an adopted practice triggers a self-reinforcing process which demarcates the start of phase 2, the Formation phase. In this phase a dominant pattern of practices is likely to emerge, making it increasingly difficult to reverse the initial pattern of practices. During the transition from phase 2 to phase 3 - the lock-in phase - options become even more constrained, leading to a situation in which practices become fixed and gain a deterministic character: lock-in occurs. A lock-in situation is characterized by a state of stability with low incentives for internal change (Vergne \& Durand, 2010). In the context of interorganizational projects - because of their complexity and ambiguity - it seems better though to speak of quasi lock-in: a predominant set of practices which leaves some room for further development, but only in a direction commensurate with the self-reinforcement (Sydow et al., 2009). (Quasi) lock-in does not automatically result in inefficiency, but inherently over time practices are likely to become less efficient in the face of new, more efficient alternatives or changing internal or external demands (Sydow et al., 2009). To speak of quasi lock-in implies that lock-in is not absolute, but rather that one can distinguish between strong and weak lock-in situations.

In order to evaluate whether a misfit between 10 project practices and demands really is the consequence of path dependence and subsequent lock-ins, a closer look the mechanisms leading to lock-in is useful. Sydow and colleagues (2009) introduce four self-reinforcing mechanisms which are at the heart of path dependence: coordination effects, complementarity effects, learning effects, and adaptive expectation effects. Each mechanism, or any combination of the four, can lead to the creation of a path which is increasingly irreversible and eventually leads to a (quasi) lock-in situation. The notion of coordination effects builds on the idea that it pays off to follow routines and adopt practices that are widely shared and used by others. Coordination effects are the consequence of shared rule-guided behaviors. The more actors 
adopt a specific set of practices, the more efficient interaction between them becomes. Behavior of actors can thus be anticipated and reactions can be considered in advance. Through these benefits of continuous replication, practices are likely to become fixed. Standardized and routine practices enhance efficient coordination when multiple organizations perform interdependent tasks under strong time pressure (Kadefors, 1995). It also shows resemblance with the network effect (Farrell \& Klemperer, 2007).

With regard to complementarity effects, interaction between separate but interrelated practices creates synergy (Stieglitz \& Heine, 2007). The benefits of repeatedly combining interrelated practices do not simply add up, but create an additional surplus. When practices are interconnected in a way that makes it unattractive to deviate from them, these practices are likely to become fixed (Leonard-Barton, 1995). Sydow (2009) for example shows that organizations in the German TV industry find it difficult to alter the type of programs they produce, because then they would not only have to change their routines but also their relations (which have a stable, permanent character). Another example of the interrelatedness of practices is addressed in the study of Faems, Janssens, Madhok and Van Looy (2008) on the interdependence between contracts and trust in project governance. Coordination and complementarity effects often reinforce learning effects (Sydow et al., 2009).

The notion of learning effects revolves around the tendency of organizations to develop more efficient ways of working when practices are repeated. This makes it less appealing and more costly to switch to other ways of working despite the potential value of doing so. For example, organizations are less likely to turn to new partners if relationships with current partners are successful (Windeler \& Sydow, 2001). Again, practices are likely to become fixed.

Finally, adaptive expectation effects can be the result of convergence towards expectations of others (Sydow et al., 2009). From an organizational perspective, while seeking legitimacy, organizational members are more willing to adopt certain practices when they expect others to follow these practices, too. These self-reinforcing adaptive expectations create self-fulfilling prophecies in organizations. Szulanski (1996) for example shows that organizations, in trying to end up on the winners' side, copy practices because they expect others to do the same.

The theoretical arguments discussed above have been applied mainly to single organizations. In the present study they are applied in an interorganizational project context. When 10 project practices do not fit the context in which they take place, project practices are less efficient than when practices and environmental demands do match. But even when organizations experience a mismatch between practices and demands, they may be unwilling or unable to change their practices because of self-reinforcing mechanisms. Following the theoretical arguments discussed above, organizations are less likely to change their project practices if a) practices have become routine among a set of actors and as such enhance the efficiency of collaboration (coordination effect), b) a set of practices is deeply intertwined, making it unattractive to deviate from any single established practice (complementarity effect), c) if - driven by efficiency reasons - the motivation 
to incrementally improve a given set of practices is higher than the motivation to look for new, radical alternatives (learning effect), leading to sub-optimalization, or d) if actors expect from one another that they collaborate according to well-established practices, and act on the basis of these expectations (adaptive expectation effect). Following this logic, path breaking will require an interruption of these mechanisms and the restoration of choice with regard to alternative practices. All together, from a historical perspective, path dependence and subsequent lock-ins may explain at least partially misfit between contemporary 10 project practices and project demands.

\section{Methods}

\subsection{Research design and setting}

This paper is an in-depth qualitative study that adopts an approach based on the 'Gioia template' (Langley \& Abdallah, 2011; Corley \& Gioia, 2004). Such an approach is considered useful for exploring relatively uncharted territory like the history of $\mathrm{IO}$ project practices in Dutch shipbuilding. A virtue of this type of research is that it explicitly takes into account the possibility that current practices are rooted in history, i.e., are "institutionalized" to the extent that their use is rarely questioned. Although this approach is useful because of its focus on "understanding the changes people are both instigating and dealing with, and how those meanings evolve" (Langley \& Abdallah, 2011, p.213), the present paper employs this approach not as emergent as Gioia and colleagues usually apply it. The starting point of this paper is 10 project practices and demands which were searched for in advance. The emergent feature of the approach is applied in identifying the path-dependent aspects of the practices in Dutch shipbuilding projects. We elaborate more in this in our data collection and analysis section.

Following Yin (2009) we choose the Dutch shipbuilding industry as a 'revelatory' case that offers the highest potential for gaining a better understanding of the understudied phenomenon of project history. The Dutch shipbuilding industry is deemed 'revelatory' because of its long tradition in interorganizational project-based production, the high technical and organizational complexity of their projects and the important contextual changes which took place over time in this industry. Interorganizational collaboration in shipbuilding is complex due to, among others, multi-partner involvement and pressures of time and place. We focus on the period $1950-2010$ because during this period collaboration demands have changed considerably under the influence of increasing competitive pressure from low-cost countries. Besides, focusing on earlier periods would not allow for the use of oral resources. We limited our study of the Dutch shipbuilding industry to the subsectors involved in the improvement program: offshore, navy, ocean shipping, dredging and maritime subcontractors, and excluded yachting, inland shipping, fishing, harbors and aquatic sport. 


\subsection{Data collection and analysis}

Our data consists of interviews with active and retired employees of shipyards and their subcontractors. The importance of oral sources to gain a valid understanding of practices is considerable since practices are rarely written down. During the period April - July 2010 fifteen interviews were conducted with respondents who were at that moment actively involved in the Dutch shipbuilding industry and participants in the industry improvement program. These interviews serve as the primary source for providing the picture of current 10 project practices in Dutch shipbuilding. During the period July - October 2011 and August - September 2012 nine interviews were conducted with respondents formerly employed in the industry and with a maritime researcher. Together, these twenty-five interviews with employees and former employees of shipyards and their subcontractors provide information on historical and contemporary 10 project practices and demands. They also provide understanding of whether or not IO project practices and demands have changed over time and, in case of change, why and how these changes have taken place. For the interviews with retired shipbuilders we relied on purposeful sampling followed by a snowball technique, asking each informant for his recommendations as to who could best explicate the processes of interest (cf. Corley \& Gioia, 2004). Interviews lasted on average 60 minutes and were all audio-recorded and transcribed verbatim. Respondents were or had been employed by both shipyards and subcontracting firms. All interviews were semi-structured and relied on an interview protocol focusing on key events and issues within the Dutch Shipbuilding industry. To minimize respondent bias, during the interviews, we did not impose constructs or theories on respondents as some sort of preferred explanation for understanding their experiences (cf. Gioia, Corley, \& Hamilton, p. 3, 2012). Recall bias was at a minimum since most of the retired respondents were still active in some way or another in the current Dutch shipbuilding industry, for example through branch organizations or charity.

We analyze the data using constant comparison (Glaser \& Strauss, 1967), which means that the analyzing process begins during and also influences the next stages of data collection. As mentioned before, we follow Corley and Gioia (2004) in their approach of coding. Sporadic differences in coding between the researchers were resolved through discussion. During the execution of the research, we identified initial constructs in the data from our interviews and grouped them together into empirical observations. From this open coding we started to construct second-order themes between these concepts which were historical and contemporary IO project practices and demands. After this categorization into our objects under study, we were able to; firstly, describe how 10 project demands in the Dutch shipbuilding have developed in the time period 1950 - 2010. And secondly, take stock of the practices in Dutch shipbuilding that either changed or remained the same over time. The more emergent part of the analysis appeared in our axial coding, which is understood by Gioia et al, (2012) as seeking for connections and 
divergences among the categories. This step resulted in examining to what extent IO project practices were path-dependent.

We identified 10 project practices as path-dependent when, firstly, they were in a misfit with the current set of IO project demands and, secondly, we were able to identify (combinations of) the four self-reinforcing mechanisms described in the theoretical section. The focus on misfitted practices is driven by the notion that inefficiency is a feature of path-dependency (Sydow et al., 2009). Misfit was identified based on the experienced problems and the goals of the maritime improvement program. We searched for the self-reinforcing mechanisms as antecedents of lockin. As an example, we coded the following quote of a retired shipbuilder about the troublesome improvement in the collaboration with subcontractors as a coordination effect:

"That question of who was to blame was hopeless, especially in the traditional discussions.

That's what I mean with trouble: accepting the new reality of a role. That's not easy."

This quote shows that shipyards and subcontractors worked according to certain rules or routines (discussing responsibility for things that had gone wrong) that were fixed to such an extent that it became difficult to switch to other rules or routines. Our final data structure is depicted in figure 1. The process of analysis was iterative in nature until we had a clear understanding of the relationships in our data and further interviews could not provide new insights.

$<<$ Insert figure 1 about here $>>$

\section{Findings}

In order to describe the developments in 10 project practices and demands in the Dutch shipbuilding industry between 1950 and 2010, we first describe changes in both IO project practices and demands by putting their historical and contemporary accounts next to each other. These accounts are based on interviews with respondents both actively and formerly employed in the industry. This is shown in tables 1 and 2. In table 3 we present evidence supporting our interpretations of project practices and demands. Next, we discuss the path-dependent aspects of these $1 O$ project practices.

\subsection{Development of IO project demands in the Dutch shipbuilding industry}

In the 1950s and 1960s, the economy of the Netherlands was gradually improving. After WWII, there was a recovery period during which there were plenty of orders for shipyards and high profit margins. The volume and number of ships constructed increased but the technical development lagged behind relative to international standards. One of the retired shipbuilders stated that this was illustrated by the relatively late transition from the traditional riveting of steel plates (a construction method at which two workers hammer both ends of a steel pin until it is rounded) to the general use of welding (the process of amalgamating two steel plates into one by melting the 
two pieces and adding a filler material). The shipbuilding industry was and is highly sensitive to cyclical economic fluctuations due to its dependence for project orders on shipping companies and ship owners. Both active and retired shipbuilders indicated that this is the case. This market condition does not seem to have changed over the years. Firms other than the shipyards taking part in projects mostly acted as suppliers (“jobbers”) rather than co-makers. In other words, they supplied pre-specified parts or components but they did not perform much work on the ship itself. Consequently, the interdependence between firms was relatively low. However, the present-day situation is characterized by a strong increase in the outsourcing of work to specialized subcontractors due to the fact that vessels have become technologically more complex and knowledge intensive. This results in high interdependence between organizations during the production process. As the retired shipbuilders stated, this was not the case around the period 1950-1970. The type of vessels built at that time had relatively low levels of technical complexity. As a result, there was hardly a need for the shipyard to in-source technical know-how. Many of the retired respondents pointed out that before the 1980s the shipbuilding industry was still seen according to standards of traditional crafts, i.e., tasks were assumed to be executed in terms of craftsmanship and production was a matter of the experience of the craftsman. This longestablished environment was described by one of the retired shipbuilders as follows:

"We built ships since the start of this era. At the beginning of the seventh century we were the biggest shipbuilder of Europe, maybe in the world. It's a pretty traditional market."

The ethos of the industry revolved around building ships rather than manufacturing capital goods. This was mainly attributed to market conditions in which the Dutch shipbuilding industry produced relatively simple, large vessels like tankers and bulk carriers. The production time of ships was relatively long, resulting in low time pressure. Nowadays, shipbuilding is characterized by a modern industrial orientation, i.e. standardization and fine-tuning of the production cycle which is illustrated by the adoption of section-wise construction and the use of computer-aided design. This change in orientation started roughly from the 1980s onwards. Time pressure on project completion increased due to the shortening of production cycles and profit margins decreased under the influence of global competition, which was spurred by the rise of Asian economies like Japan back then and China today. This trend forced the Dutch shipbuilding industry to re-focus on niche markets and direct its efforts to specialization and innovation. In comparison to European competitors, the Dutch shipbuilding industry has been able to maintain its position. However, as described in a British research report, the position of the Dutch shipbuilding industry remained precarious:

"The Netherlands nearly lost its shipbuilding industry in the late 1980s but appears to have fully recovered in the 1990s, though it saw a sharp drop-off in sales in 2003. The Dutch market was in 2005 roughly where it was in the late 1970s" (RAND Corporation, 2005). 
Summarizing, we observe a coherent set of 10 project demands which have undergone major changes over the past decades. Both organizational and technological complexity of IO projects have increased because of an increase in the number of project partners involved and the interdependency among them, technological developments and more intense time pressure on the production of vessels. Because of these factors, which are amplified by a decrease in profit margins and a continuous sensitivity of the sector to economic fluctuations, the current Dutch shipbuilding industry can be characterized as a versatile and dynamic environment. An overview of these historical and contemporary project demands is summarized in table 1.

$<$ Insert table 1 about here $>>$

\subsection{Development of IO project practices in the Dutch shipbuilding industry}

During the second half of the twentieth century shipyards performed most of the work in-house. As a result, there was less urgency to coordinate and monitor other firms. One of the retired shipbuilders illustrated this situation as follows:

"We employed everyone, our own painters, scaffold builders, and ship carpenters. (...) We outsourced very little."

Shipyards tended to conduct most of the project work in-house and there was a high communal pride in the work. In addition to this, whenever problems in the project appeared, for example with quality, delivery times or budget, these were solved at a higher management level. One of the retired shipbuilders explained why:

"It could be that the project manager had a row with the project manager of the subcontractor, for example, because he lagged behind on delivery times or quality. But because sooner or later you had to deal with each other again, the board of directors had to make sure the conflict didn't get out of hand."

Over time, the outsourcing of project work to subcontractors has increased significantly as a response to shorter production cycles, increased time pressure, and greater technical complexity. The increased outsourcing was driven by the need for cost reduction caused by the project demand of price competition on the global shipbuilding market. However, while outsourcing more and more work, the shipyards have clung to their orchestrating role in the process. This may have led to the formal and low trust nature of their current relations with subcontractors, as illustrated in the following quote: 
"Those alleged reliable partners of ours had the market so nailed up that every attempt to involve third parties was nipped in the bud. That's where we pay extra. They just paid them [the "third parties"] to either not tender or just above their offer. They received a fee for that which was then on-charged to us." - Purchasing manager Shipyard

The shipyards have always been and still are the central actors in a project. They coordinate and monitor the activities of subcontractors, communicate exclusively with the end customer, and also bear most of the risk on the project. It is this unbalanced risk-taking that is the major source of problems between shipyards and subcontractors, as put by one of the retired shipbuilders:

"When the yard's project manager and the subcontractor's project manager share the responsibility, you can get improvement. But that discussion never came to a good end. Nobody wanted to make concessions. Then it stops. As long as responsibility resides with one party, that party will take the decisions. Because he is responsible for profit and loss."

Early in the second half of the twentieth century, 10 project practices in the Dutch shipbuilding were characterized by flexible contract application and by relations primarily based on trust. This was also noted by a maritime researcher:

"They saw each other often in the church on Sunday. Trust developed there. The contract is a document, you need to have it, but it is only for emergencies. You do not use it in every-day practice."

However, this changed notably over time because, for example, having more subcontractors impeded the development of personal relationships with everyone. Nowadays, contracts are more detailed and broader in scope. Shipyards and subcontractors nowadays tend to write extensive and elaborated contracts and apply them in a rigid manner.

Another finding is the decay of the common pride that formerly characterized the Dutch shipbuilding industry. Some of the contemporary actors expressed enduring pride in their work which is mainly displayed in an attitude in which the overall project success takes pride of place. Others however emphasize self-interest, either financial or otherwise, even if at the expense of the project. Pursuing one's self-interest is illustrated by the following quote:

"People are more and more looking up their own alley. This part is finished within the allocated hours so I am done with it. If I have to step it up to make it more efficient somewhere else, I will put in more hours and I am evaluated by that so I rather don't." Technical manager Shipbuilding 
Notwithstanding the practice of prioritizing one's self-interest, there is a strong emphasis on informal personal and organizational networks in which participants involved in the 10 project enhance their communications, direct their efforts and observe their attitudes. This 10 project practice of operating through informal personal and organizational networks does not seem to have changed over time. In current shipbuilding projects that do operate in a flexible and informal way, respondents indicate that the pleasant and successful collaboration is a consequence of the long-lasting relationships between yards and suppliers. However, this is no longer a widespread practice in the industry.

Summarizing, we observe that some practices have changed during the past five decades whereas other practices remained relatively stable. $1 O$ project practices have shifted from a more informal way of organizing work and coordinating relations to a more formal manner of collaboration, with a stronger emphasis on contracts. In addition to this, shipyards now outsource significantly more of the work to subcontractors.

Examples of practices that have remained more or less the same over the past decades are the central role of the shipyard, the skewed financial responsibility for projects, the importance of informal networks, and referral of problems to higher hierarchical levels. An overview of these historical and contemporary project practices is summarized in table 2.

$<<$ Insert table 2 about here $>>$

Although 10 project practices have changed to some extent, these changes did not always increase the fit with the changing demands set by the task environment. Furthermore, there are also practices that remained the same over the period of 1950-2010; either causing a misfit or allowing an already existing misfit to continue. Based on practices considered appropriate by the project participants in the improvement program mentioned earlier in the paper, we consider four contemporary practices to be at a misfit with the current set of 10 project demands. First, the complete financial responsibility at the account of the shipyard, which remained the same over time, does not fit with the current project demands of higher interdependence between project participants and lower profit margins in the Dutch shipbuilding industry. The current set of 10 project demands calls for a more shared risk distribution or, in the words of one of the respondents in this study:

"The more product complexity increases, and the available time decreases, the more you have to move towards collaboration in which risks are shared. The same goes for financial risks. That is a learning process for both parties. It also means there has to be trust, you let them look behind the scenes, and people have to dare. And I have to admit it is laborious." - Commercial Director Shipyard 
In addition to this, the goal of the improvement program of increased knowledge sharing in IO projects is unlikely to be achieved when financial responsibility resides with one party. Second, the shipyard's role as lead organization in the $1 O$ project, which remained the same over time, does not fit with the increased number of partners involved in a project and the higher technical complexity of vessels. These contemporary demands make it difficult for one single firm to coordinate the entire project and bring together all the required technical know-how. This is formulated by the program director of the maritime improvement program as follows:

"We used to know that a guy was pulling cables on a project but we didn't know exactly how he was doing besides his remark: 'it is going okay'. When you know that better you can take better decisions."

Third, the stronger emphasis on self-interest, which increased over time at the expense of the common pride in shipbuilding projects, is at a misfit with the increased competitive pressure from Asia, in combination with the modern industrial orientation on producing turn-key maritime products appropriate for the complex products in which the Dutch shipbuilding now specializes. These demands necessitate a holistic project-oriented attitude of all partners involved in order to achieve the goal of a stronger competitive position of the Dutch shipbuilding industry. One of the respondents stated:

"I used to check all the drawings but eventually I thought: this is not my job, I don't get paid for this. So now we use more materials, it increases the cost price"

Shipbuilding projects can benefit from participants that align their self-interest more with the broader interorganizational project than their organization-wide interest. Finally, the stronger reliance on formal contracting is assumed to be at a misfit with the demands of higher time pressure and shorter production cycles in shipbuilding projects. More formalized contracting makes it difficult to quickly react to changing project conditions and efficiently deal with the increased time pressure and shorter production cycles. One of the retired employees in our study formulated the problematic nature of this practice as follows:

"Currently, I see how lawyers get bogged down in contracts, that they are nitpicking each other. That is nothing but distraction from the real goal: to build a ship together."

$<<$ Insert table 3 about here $>>$

\subsection{Self-reinforcing mechanisms in 10 project practices}

We will assume path dependence only to be probable when there is a misfit between current IO project practices and project demands. This is in line with the assumption that path dependence 
inherently leads to inefficiency, or sub-optimalization. In the preceding text we have identified a current misfit between $1 O$ project demands and the following $I O$ project practices: a) the shipyard bears the major risks and full responsibility towards the end customer for delivering the vessel on time and according to specifications; b) the shipyard acts as the lead organization; c) shipyards and subcontractors pursue predominantly their own (financial) interests; and d) shipyards and subcontractors contract in a formal, rigid way. While the former two practices have remained stable over the past 60 years, the latter two have changed substantially during this period.

The criterion we use to identify practices as actually being path dependent is whether one of the self reinforcing mechanisms, or a combination of these mechanisms, has plausibly influenced the development or stagnation of project practices. We distinguish between two possibilities: a) we observe a change in project practices over time which is not in line with the evolution of project demands, or b) we see stagnation of a project practice in spite of a lack of fit with historical and/or contemporary project demands. In the first instance we see the development to the situation of lock-in, in the second case the lock-in was already present.

If we consider the first ineffective practice (shipyard bearing full risk and responsibility), our findings indicate that project demands have changed over time while this practice has not changed accordingly. In a situation where subcontractors represent about $70 \%$ of the total costs of producing a vessel, it seems justified for subcontractors to bear at least part of the risk and responsibility. However, the current practice can be understood from a path dependence point of view. Because the shipyard has always carried full financial responsibility it has learned to take on that role efficiently. If subcontractors would take a share in that responsibility, they would have to develop new skills (e.g., communication and negotiation with the end customer, monitoring the actions and efforts of other subcontractors, skills related to funding the project and dealing with financial risks) in order to carry out that new role:

"In the pricing of the project you have to take into account that things can go wrong. [...] The subcontractor is not used to that; yeah, their own small responsibility but never as part of the bigger process." - Retired shipbuilder

Shipyards and subcontractors have learned to play their own specific role efficiently, and changing these roles would require non-trivial adaptation problems. This suggests that both coordination and learning effects are at work in causing this practice to be persistent over time. Because the practice has remained stable over the past 60 years, reinforcement has continued over a long time period, resulting in a strong lock-in which is difficult to break.

Another, related, IO project practice that has not changed over time is the shipyard acting as the lead organization. This practice can be interpreted as reinforcing due to coordination and learning 
effects on the one hand and adaptive expectation effects on the other hand. The coordination and learning effect reside in the division of roles in which the shipyard acts as the leading organization, a constellation of roles that is perceived by both shipyards and subcontractors as normal and efficient. Because the shipyard is the leading party during every project, they have mastered a certain efficiency and standardization regarding the coordination of collaboration. Similarly, subcontractors have become proficient in their role of being responsible for their specific contribution. The adaptive expectation effect lies in the persistent division of roles due to which project participants expect this same division of roles to occur in new projects. A subcontractor participating in a new project would automatically assume the shipyard to be in the lead, mainly because other parties also do so. Again - similar to the practice of the shipyard bearing full risk and responsibility - this practice has reinforced itself over a long time period and has become strongly institutionalized:

“The discussion of the subcontractors becoming more central started somewhere in '85. Whenever the subject was discussed everyone backed out at the end of the day and said: No, let's stick to the old way." - Retired shipbuilder

The combination of the shipyard bearing all the risk and financial responsibility and acting as lead organization constitutes a complementarity effect: the interrelatedness of these practices makes it problematic to deviate from either one. For parties that bear financial risk, it seems logical to take on a leading role, as the retired shipbuilders pointed out. A subcontractor may feel no urgency to become more central if he has no financial responsibility, and may be reluctant to take responsibility if not given the central power and authority to manage the collaboration process. Due to this complementarity effect, this set of practices has become fixed. While each practice on its own is self-reinforcing, the interrelatedness of the practices strengthens these self-reinforcing effects, resulting in a very strong lock-in.

Next we discuss the two practices that have changed over time and which we consider ineffective given the current project demands. The current trend that both shipyards and subcontractors mainly pursue their own interests intuitively conflicts with the current demand stemming from the organizations' increasing mutual dependency. Comparing this present-day situation with the situation a few decades ago, it appears that in the old situation the range of options was broader than in the current situation. While earlier shipyards and subcontractors could choose between pursuing self-interest on the one hand and working for a common cause on the other hand, the current situation seems to predispose them to neglect the greater cause and pursue first and foremost their (financial) self-interest. Our results indicate that this process is at least partially triggered by adaptive expectations. Because of the involvement of multiple, legally independent organizations - that implicitly or explicitly have separate and conflicting financial interests - the common expectation has become that organizations will give priority to protecting these interests. 
When organizations expect their partners to act in a self-interest seeking manner, they are more likely to display the same behavior, which will be observed by the others, thus creating a selffulfilling prophecy. This vicious circle leads to a situation where behaving opportunistically is considered the only appropriate course of action, so that lock-in occurs:

"A shipyard that accepts a price for a vessel, that's often under pressure, will try to get that money back from the subcontractors. Well, that's contrary to the idea of co-makership, which is the motto. That was a hundred years ago a problem, it was fifty years ago a problem and it's still a problem." - Retired shipbuilder

"That guy [shipyard employee] has been molded that way over twenty, thirty years. You cannot change him anymore, that's a non-starter. He has been trained to exploit subcontractors, and that is what he will be doing for the rest of his career." - Subcontractor

Related to this IO project practice is the practice of formal contracting. While earlier interaction between shipyards and subcontractors was of a more informal nature, the current situation is characterized by more formal ways of interaction, including formal contracting. Our interviews indicate that this practice has co-evolved with the practice of pursuing self-interest. If organizations expect others to behave opportunistically, they will try to safeguard their own interests. This can be accomplished by writing extensive, detailed contracts in which roles and responsibilities of each partner are made explicit. The interrelatedness of these two practices suggests that complementarity effects play a role in reinforcing a process in which options have narrowed down, eventually leading to a lock-in situation. This lock-in situation is characterized by organizations pursuing mainly self-interests, and relying on formal contracting to safeguard against opportunistic partner behavior.

"Practice has changed from having a common goal towards crafting contracts with hidden meanings which I can use to my own advantage." - Retired shipbuilder

In sum, our results suggest that the current misfitted practices can at least partially be explained by path-dependent processes. Shipyards bear full risk and responsibility and act as lead organization because over time they have learned to perform this task efficiently, which fosters coordination of and communication between shipyards and subcontractors during the process of building complex vessels. Shifting responsibility towards subcontractors would require substantial investments to master new, unfamiliar skills both on the account of the shipyards and the subcontractors. Shipyards and subcontractors pursue self-interest and rely on formal contracting because they believe that the others follow this strategy as well, creating a vicious circle in which these practices reinforce one another to the point that other options are considered inefficient. 


\section{Conclusion and discussion}

The starting point of this paper is the acknowledgement by industry actors in Dutch shipbuilding that contemporary 10 project practices do not fit contemporary IO project demands. In this paper we have explored path-dependent explanations for this misfit. Focusing on the practices that do not fit contemporary demands, we have identified continuity in some practices and change in others. Both persistent and changed practices seem to be influenced by combinations of selfreinforcing mechanisms. All in all, our analysis suggests that the misfit has at least partially been shaped by historical developments.

To understand the misfit between demands and practices in Dutch shipbuilding projects, we complemented contingency theory with the path dependence perspective to avoid the static and a-historical stance of the former theory. In doing so, we advance the field in several ways. First, we empirically identify theoretically proposed mechanisms (Sydow et al., 2009) which trigger path dependence. Most empirical research on path dependence tends to examine path dependence in the sense of 'history matters' only, without entering into details on self-reinforcing mechanisms (Vergne \& Durand, 2010). Our findings suggest that indeed the proposed mechanisms play a significant role in explaining lock-in situations and subsequent misfit in an 10 project context. In addition, we suggest a refinement of the proposed mechanisms by taking into account that the mechanisms operate not in isolation but in an interrelated manner. It seems precisely to be this interrelatedness between path dependence mechanisms that makes misfit so difficult to remedy in the Dutch shipbuilding industry. Thus, similar to interrelated practices, interrelated mechanisms form a configuration which creates complementarity effects. Second, our study demonstrates that path dependence can lead to incremental or creeping change. As we have shown, some 10 project practices have changed over time in a direction counter to what one would expect given the contemporary environmental demands. During this process, the availability of alternative practices has decreased, ultimately leading to a lock-in situation. This process - which we label path-dependent adaptation - is counter to contingency theory's assumption that organizations change their practices on short notice to bring them in line with changing environmental demands. So while contingency theory assumes organizations to change practices to regain fit, path dependence helps explain why organizations sometimes change their practices 'in the wrong direction', thereby creating or sustaining misfit. Third, we extend path dependence literature by applying its insights to the context of IO projects. Most research on path dependence pertains to organizations rather than goal-directed networks of organizations, but we show that insights on path dependence can be generalized to this context as well. Our fourth and final contribution is a critical note on path dependence models that describe path dependence as a three-stage process (e.g., Sydow et al., 2009, p. 692). Such models may be less suited to explain situations of early lock-ins. Some 10 project practices in Dutch shipbuilding have remained unaltered over time, suggesting that the available range of alternative practices has been limited since the beginning. This seems to call into question the idea of 'critical junctures', the moments 
at which practices become subject to self-reinforcing mechanisms. Though these models aid in explaining why these practices have not changed over time, they fail to explain how early lock-in situations are reached. Explanations other than path dependency may be needed here.

\section{Implications and directions for future research}

Based on our findings we suggest two practical implications for project managers, in specific change agents (e.g., Seo \& Creed, 2002), seeking to change practices. First, they should be well aware of historical influences on contemporary practices. Historical influences hamper their ability to break away from these practices because they follow a more or less pre-determined path. To change these practices would require path breaking. The idea of path breaking however is somewhat self-contradictory since path dependence is a process in which organizations or industries face difficulties in changing their practices successfully. A minimum condition would be the development of alternative practices, and the interruption of the discussed self-reinforcing mechanisms. An approach to deliberately break paths might be critically reflection on taken-forgranted practices, for example via assumption surfacing (Kettinger, Teng, \& Guha, 1997). On top of that change agents should consider the development of superior alternative practices (cf. Arthur, 1994). Second, change agents should be aware of the interrelatedness of practices as well as of the path-dependence mechanisms underlying their persistence. Interrelatedness of practices implies that one cannot change one practice without influencing the other. To successfully change practices then requires a configurational or holistic approach (e.g., Clarke, 1999). Such an approach would consider the complexity and interrelatedness of practices and develop initiatives aimed at changing sets of practices rather than single ones. Interrelatedness of path-dependence mechanisms implies that multiple causes for a lack of adaptation to project demands must be addressed simultaneously. For instance, to change the practice of the shipyard bearing all the risk in a project, the suppliers involved should learn to master this role, but the mutual tacit assumptions concerning the roles of shipyard and suppliers should also be addressed. The difficulty to achieve all these changes simultaneously may well explain why improvement initiatives like the one mentioned in the introduction to this paper have a high risk of failure.

There are some limitations to our study which suggest opportunities for future research. The most salient limitation is of a methodological nature. In trying to discover path-dependent explanations for the current misfit, we have relied on subjective, oral sources. This method makes it difficult to objectively establish if the current misfit is indeed the result of path dependence, and to ascertain which situations qualify as lock-ins. In response to this issue experimental studies as proposed by Vergne and Durand (2010) could be performed, but these would in turn be limited in their ability to incorporate historical aspects, especially at the industry level, like in the shipbuilding sector that formed the context of our study. A related issue concerns our single-method approach, which limits the possibility to triangulate data. The use of documents and archival data could provide 
additional insights. As IO project practices, especially informal ones, are rarely written down such an archival approach in our view should be combined with oral history. Another limitation concerns respondents' recall bias, to the extent that they may better recall positive events than negative ones, creating an inaccurate picture of historical practices and demands and their development. However, respondents did not give the impression to believe that everything was better in the old days, and in some cases concluded that the current problems are no different from the problems 60 years ago. In addition, many of the retired shipbuilders we interviewed are still active in industry associations, enabling them to reflect on both historical and contemporary practices and demands. Considering these various limitations, future research could benefit from developing more objective measures of the self-reinforcing mechanisms, and from applying a multi-method approach combining the use of documents, archives, and statistical analysis.

\section{References}

Ahola, T., Laitinen, E., Kujala, J., \& Wikström, K., 2008. Purchasing strategies and value creation in industrial turnkey projects. International Journal of Project Management, 26(1), 87-94.

Aldrich, H., E., \& Pfeffer, J., 1976. Environments of Organizations. Annual Review of Sociology, 2, 79-105

Arthur, W. B., 1994. Increasing returns and path dependency in the economy. Ann Arbor: University of Michigan Press.

Bakker, R.M., Knoben, J., Vries, N. de, \& Oerlemans, L.A.G., 2011. The nature and prevalence of interorganizational project ventures: Evidence from a large scale field study in the Netherlands 2006-2009. International Journal of Project Management, 29(6), 728-739.

Bechky, B. A., 2006. Gaffers, gofers, and grips: role-based coordination in temporary organizations. Organization Science 17(1), 3-21. Doi: 10.1287/orsc.1050.0149

Beckman, C. M., \& Burton, M. D., 2008. Founding the future: Path dependence in the evolution of top management teams from founding to IPO. Organization Science, 19, 3-24.

Clark, P. \& Rowlinson, M., 2004. The Treatment of History in Organisation Studies: Towards an 'Historic Turn'? Business History 46(3), 331 - 352. Doi: 10.1080/0007679042000219175

Clarke, A., 1999. A practical use of key success factors to improve the effectiveness of project management. International Journal of Project Management, 17(3), 139-145. 
Collier, R. B., \& Collier, D., 1991. Shaping the political arena: Critical junctures, the labor movement, and regime dynamics in Latin America. Princeton, NJ: Princeton University Press.

Corley, K. G. \& Gioia, D. A., 2004. Identity Ambiguity and Change in the Wake of a Corporate Spin-Off. Administrative Science Quarterly 49(2), 173-208.

Dille, T., \& Söderlund, J., 2011. Managing inter-institutional projects: The significance of isochronism, timing norms and temporal misfits. International Journal of Project Management, 29(4), 480-490.

Donaldson, L., 1987. Strategy and structural adjustment to regain fit and performance: In defence of contingency theory. Journal of Management Studies, 24(1), 1-24.

Drazin, R., \& Van de Ven, A., 1985. An examination of alternative forms of fit in contingency theory. Administrative Science Quarterly, 30, 514-539.

Duncan, R., B., 1972. Characteristics of Organizational Environments and Perceived Environmental Uncertainty. Administrative Science Quarterly, 17(3), 313-327

Engwall, M., 2003. No project is an island: linking projects to history and context. Research Policy 32(5), 789-808. Doi: Pii S0048-7333(02)00088-4

Eskerod, P., 1996. Meaning and action in a multi-project environment: Understanding a multiproject environment by means of metaphors and basic assumption. International Journal of Project Management, 14(2), 61-65.

Faems, D., Janssens, M., Madhok, A., \& Van Looy, B., 2008. Toward an integrative perspective on alliance governance: connecting contract design, trust dynamics, and contract application, Academy of management Journal, 51(6), p. 1053-1078.

Farrell, J., \& Klemperer, P., 2007. Coordination and lock-in: Competition with switching costs and network effects. In Armstrong, M., \& Porter, R. H., Handbook of Industrial Organization (vol. 3, pp. 1967-2072). Amsterdam: North-Holland.

Gioia, D. A., Corley, K. G., \& Hamilton, A. L., 2012. Seeking qualitative rigor in inductive research: Notes on the Gioia methodology. Organizational Research Methods, 00(0), 1-17.

Glaser, B. \& Strauss, A., 1967. Discovering Grounded Theory. Chicago, IL: Aldine. 
Goodman, R. A., \& Goodman, L. P., 1976. Some management issues in temporary systems: A study of professional development and manpower-the theatre case. Administrative Science Quarterly, 21(3), 494-501.

Gresov, C., 1989. Exploring fit and misfit with multiple contingencies. Administrative Science Quarterly, 34(3), 431-453.

Huxham, C., 2003. Theorizing collaboration practice. Public Management Review, 5(3), 401 423).

Jensen, C., Johansson, S., \& Löfström, M., 2006. Project relationships: A model for analyzing interactional uncertainty. International Journal of Project Management, 24(1), 4-12.

Jones, G. \& Khanna, T., 2006. Bringing history (back) into international business. Journal of International Business Studies 37, 453 - 468. Doi: 10.1057/palgrave.jibs8400198

Jones, C. \& Lichtenstein, B., 2008. Temporary inter-organizational projects: how temporal and social embeddedness enhance coordination and manage uncertainty. In Cropper, S., Ebers, M., Huxham, C. \& Smith Ring, P. (Eds.), The Oxford Handbook of InterOrganizational Relations (pp. 231-255). Oxford, UK: Oxford University Press.

Kadefors, A., 1995. Institutions in building projects: Implications for flexibility and change. Scandinavian Journal of Management, 11(4), 395-408.

Kettinger, W. J., Teng, J. T. C., \& Guha, S., 1997. Business process change: A study of methodologies, techniques, and tools. MIS Quarterly, 21, 51-80.

Kostova, T., \& Roth, K., 2002. Adoption of organizational practices by subsidiaries of multinational corporations: Institutional and relational effects. Academy of Management Journal, 45(1), $215-233$.

Langley, A., \& Abdallah, C., 2011. Templates and turns in qualitative studies of strategy and management. In Bergh, D., \& Ketchen, D. (Eds.), Building methodological bridges: Research methodology in strategy and management (vol. 6, pp. 201-235). Bingley, UK: Emerald Group.

Lawrence, P., \& Lorsch, J., 1967. Organization and environment. Boston, MA: Harvard Business School Press. 
Leonard-Barton, D., 1995. Wellsprings of knowledge. Boston: Harvard Business School Press.

March, J. G., \& Simon, H. A., 1958. Organizations. New York: Wiley.

Mintzberg, H., 1978. Patterns in strategy formation. Management Science, 24, 934-948.

Nelson, R. R., \& Winter, S. G. 1982. An evolutionary theory of economic change. Cambridge, MA: Harvard University Press.

Nooteboom, B., 1997. Path dependence of knowledge: Implications for the theory of the firm. In L. Magnusson \& J. Ottosson (Eds.) Evolutionary economics and path dependence: 57-78. Cheltenham, UK: Edward Elgar.

Phillips, N., Lawrence, T. B., \& Hardy, C., 2000. Inter-organizational collaboration and the dynamics of institutional fields. Journal of Management Studies, 37(1), 23-43.

Polidoro, F., Ahuja, G., and Mitchell, W., 2011. When the social structure overshadows competitive incentives: The effects of network embeddedness on joint venture dissolution. Academy of Management Journal, 54, pp. 203 - 223.

RAND Corporation., 2005. Differences between military and commercial shipbuilding. Implications for the United Kingdom's Ministry of Defence (N/A MG-236-MOD).

Schreyögg, G., \& Sydow, J., 2011. Organizational path dependence: A process view. Organization Studies, 32(3), 321-335.

Schreyögg, G., Sydow, J., \& Holtmann, P., 2011. How history matters in organisations: The case of path dependence. Management \& Organizational History, 6(1), 27-43.

Scott, W. R., 1995. Institutions and organizations. Thousand Oaks, CA: Sage.

Seo, M., \& Creed, W. E. D., 2002. Institutional contradictions, praxis, and institutional change: A dialectical perspective. Academy of Management Review, 27(2), 222-247.

Shenhar, A. J., \& Dvir, D., 1996. Toward a typological theory of project management. Research Policy, 25(4), 607-632.

Siggelkow, N., 2001. Change in the presence of fit: the rise, the fall, and the renaissance of Liz Claiborne. Academy of Management Journal 44(4), 838-857. Doi: 10.2307/3069418 
Stieglitz, N., \& Heine, K., 2007. Innovations and the role of complementarities in a strategic theory of the firm. Strategic Management Journal, 28, 1-15.

Sydow, J., 2009. Path dependencies in project-based organizing: Evidence from television production in Germany. Journal of Media Business Studies, 6(2), 123-139.

Sydow, J., Schreyögg, G., \& Koch, J., 2009. Organizational path dependence: Opening the black box. Academy of Management Review, 34(4), 689-709.

Szulanski, G., 1996. Exploring internal stickiness: Impediments to the transfer of best practices within the firm. Strategic Management Journal, 17(Winter Special Issue), 27-43.

Tushman, M. L., \& Nadler, D. A., 1978. Information processing as an integrating concept in organizational design. Academy of Management Review, 3(3), 613-624.

Tushman, M. L., \& Romanelli, E., 1985. Organizational evolution: A metamorphosis model of convergence and reorientation. In Cummings, L. L., \& Staw, B. (Eds.), Research in organizational behavior (vol. 7, pp. 171-222). Greenwich, CT: JAI Press.

Usdiken, B., \& Kieser, A., 2004. Introduction: History in Organisation Studies. Business History, 46(3), 321-330

Van de Ven, A. H., 1979. Review of Howard Aldrich, Organizations and environments. Administrative Science Quarterly, 24, 320-326.

Vergne, J., \& Durand, R., 2010. The missing link between the theory and empirics of path dependence: Conceptual clarification, testability issue, and methodological implications. Journal of Management Studies, 47(4), 736-759.

Voogd, C. de, 1993. The decline of shipbuilding and other industries. (Doctoral dissertation, Erasmus University Rotterdam, The Netherlands).

White, D., \& Fortune, J., 2002. Current practice in project management: An empirical study. International Journal of Project Management, 20(1), 1-11.

Wiersema, M. F., \& Bantel, K. A., 1993. Top management team turnover as an adaptation mechanism: The role of the environment. Strategic Management Journal, 14(7), 485-504. 
Windeler, A., \& Sydow, J., 2001. Project networks and changing industry practices: Collaborative content production in the German television industry. Organization Studies, 22(6), 10351060.

Yin, R. K., 2009. Case study research. Thousand Oaks, CA: Sage Publications. 
Table 1. Overview of IO project demands

\begin{tabular}{|l|l|}
\hline \multicolumn{1}{|c|}{ Historical demands } & \multicolumn{1}{c|}{ Contemporary demands } \\
\hline Few partners involved in a project & Many partners involved in a project \\
\hline $\begin{array}{l}\text { Low interdependence } \\
\text { Subcontractors only supplying } \\
\text { components) }\end{array}$ & $\begin{array}{l}\text { High interdependence } \\
\text { (Subcontractors installing } \\
\text { components on board) }\end{array}$ \\
\hline Low technical complexity of vessels & High technical complexity of vessels \\
\hline $\begin{array}{l}\text { Low time pressure, } \\
\text { long production cycles }\end{array}$ & $\begin{array}{l}\text { High time pressure, } \\
\text { short production cycles }\end{array}$ \\
\hline High profit margins & Low profit margins \\
\hline $\begin{array}{l}\text { Industrial orientation similar to } \\
\text { traditional craft of constructing vessel }\end{array}$ & $\begin{array}{l}\text { Industrial orientation similar to } \\
\text { producing modern maritime product }\end{array}$ \\
\hline Sensitivity to economic fluctuations & Sensitivity to economic fluctuations \\
\hline
\end{tabular}


Table 2. Overview of IO project practices

\begin{tabular}{|l|l|}
\hline \multicolumn{1}{|c|}{ Historical practices } & \multicolumn{1}{c|}{ Contemporary practices } \\
\hline Trust-based coordinating & Less trust-based coordinating \\
\hline Emphasizing informal contracting & Emphasizing formal contracting \\
\hline Emphasizing common pride & $\begin{array}{l}\text { Emphasizing (financial) self-interest } \\
\text { by some participants, lasting pride by } \\
\text { other participants. }\end{array}$ \\
\hline $\begin{array}{l}\text { Shipyard acting as lead organization } \\
\text { in-house (work distribution shipyard - } \\
\text { subcontractor: 70-30) }\end{array}$ & $\begin{array}{l}\text { Shipyard acting as lead organization } \\
\text { work (work distribution shipyard - } \\
\text { subcontractor: 30-70) }\end{array}$ \\
\hline $\begin{array}{l}\text { Operating through informal networks } \\
\text { (personal and organizational level) }\end{array}$ & $\begin{array}{l}\text { Operating through informal networks } \\
\text { (personal and organizational level) }\end{array}$ \\
\hline $\begin{array}{l}\text { No risk sharing, financial } \\
\text { responsibility at the shipyard }\end{array}$ & $\begin{array}{l}\text { No risk sharing, financial } \\
\text { responsibility at the shipyard }\end{array}$ \\
\hline $\begin{array}{l}\text { Problems referred to higher } \\
\text { hierarchical levels }\end{array}$ & $\begin{array}{l}\text { Problems referred to higher } \\
\text { hierarchical levels }\end{array}$ \\
\hline
\end{tabular}


Table 3. Data supporting interpretations of IO project practices and demands

\begin{tabular}{ll}
\hline \begin{tabular}{l} 
Data supporting interpretations of project practices and demands \\
\hline Theme
\end{tabular} & Representative quotes \\
\hline Historical & Low interdependence / Few partners involved in the project: "The most \\
project & important thing is that in that time the yard wanted to do everything on its own. \\
demands & They had their own painting companies, own electrical division. They \\
& controlled everything by themselves." (-retired shipbuilder) \\
& (Positive) Economic sensitivity I Long production cycles: "And my boss \\
& said to me 'there's a bunch of papers, good luck'. Those were all specifications \\
& for ships. In that period economy was doing so well that shipping companies \\
& stood in line for shipyards. We simply couldn't find the time to handle all the \\
& customer requests." (-retired shipbuilder)
\end{tabular}

(Negative) Economic sensitivity: "In times of economic decline, one had to fire employees on a large scale to keep one's head above water." (Government report on Dutch maritime industry)

Contemporary High time pressure: "The pressure of work is quite high. You've got a timeproject limit that is just very tight. We work with schedules from which you know demands beforehand: well, I hope we're going to make that." (-Technical manager, Shipyard)

High interdependence / High technical complexity: "Who is designing something? Who is delivering something? Who is connecting it? Who is commissioning it? And it was very clear from the start so every time we had a discussion, we just opened the demarcation: no, it is yours. You have to sort it out. And it saved a lot of discussions. (-Project manager, electrical company) Many external partners involved: "Subcontractors became more and more important because the entire functioning of the vessel is dependent on the performance and quality of the subparts. So their importance and influence with regard to profit and risk grew immensely." (-maritime researcher) Changes in 10 project practices

\begin{tabular}{ll}
\hline Historical & Trust-based coordinating I Operating through informal networks: "There \\
project & was only one supplier, for electrical installations, that was important. That is \\
practices & called subcontractor right? I don't believe he cheated us. We had a very good \\
& relationship with him." (-Retired shipbuilder)
\end{tabular}
Emphasis on common pride: "It [shipbuilding] used to be much more goaldriven. Everybody was glowing with pride at the moment a ship sailed away for 
the first time. It has changed from a shared, common pride of that ship sailing away to how can I write my contracts in such a way that it is to my own advantage. It all has become less open. "(-Retired shipbuilder)

Operating through informal networks / Problems referred to higher hierarchical levels: "Whenever the board of directors of site $X$ came over to talk to the board of directors of site $Y$, they always dropped by at our department and said: you guys work together, we'll do the fighting at the top. You maintained good relations with those guys." (-Retired shipbuilder)

"I think that between yard and subcontractor there were always informal arrangements, it's always a matter of give and take. That one [project manager] says 'ok, if you do this task for me then I won't bother you about that thing'. It's often the most efficient way to get a result." (-Retired shipbuilder)

Emphasizing informal contracting: "The rivalry between the Dutch shipbuilders in those days was legendary. In the eyes of outsiders they were bitter rivals. Behind the written contrasts institutionalized cooperation was hidden." (-de Voogd, 1993)

Contemporary Emphasis on (financial) self-interest: "Everyone is fighting for his own project purse. And that is not unhealthy, I think. But the atmosphere is quite different. practices Because the atmosphere is no longer about how we are going to solve it but more about: if you want me to do something it will cost you." (-Head project management, electrical company)

Shipyard acting as lead organization / Less trust-based coordinating: "We are seen as the troublesome subcontractor, who tries to keep things covert, something we have to do because as soon as we tell something they take it to the competitor, and then we are left empty-handed. That just happens. Drawings are copied and given to the neighbors. What is your price? (...) Then you don't put everything on drawing." (-Contract manager, electrical company)

Emphasizing formal contracting / Emphasis on (financial) self-interest: "It is much easier if you can arrange things on the production floor, much and much easier. But today that is no longer possible. Today everything needs to be confirmed by email and backed up with pictures. That is really a trend that has become visible over the past few years. You can make informal arrangements with a person but it can have major consequences when these commitments are not met. Because when the work is not done, it costs us time and money." (- Production manager, painting company)

Shipyard acting as lead organization / degree of outsourcing / Emphasis 
on formal contracting: "The contracts between shipyard and subcontractor go pretty far, because they spell out in detail a subcontractor's functionality and supply scope, but also a demarcation list with activities. And they do that for every subcontractor. And the structure of the contract and the purchasing conditions are written down in such a way that you as a subcontractor have no say in the overall picture. The shipyard outsources $70 \%$ of the entire vessel to subcontractors, but these subcontractors have no influence on the building process. (...) No matter for what reason, if there are problems with the planning that cause you to start your work later, can deliver later, and hence need to put more time and effort in your job, you cannot call the shipyard to account for that extra time and effort." (-Head project management, electrical company) 
Figure 1 - Data structure

- Few subcontractors

- Low interdependence

- Low technical complexity

- High profit margins

- Long production cycles

- $\quad$ Shipbuilding as traditional craft

- Many subcontractors

- High interdependence

- High technical complexity

- Low profit margins

- Short production cycles

- $\quad$ Shipbuilding as industrial process

- Emphasis on trust

- Emphasis on informal relations

- Emphasis on common pride

- Work mainly conducted in house

- Problem solving at higher levels

- Importance of networks (Personal and organizational level)

- Project risk at account of shipyard

- Shipyard as lead organization

- Emphasis on distrust

- Emphasis on formal relations

- Emphasis on self-interest

- Work mainly outsourced
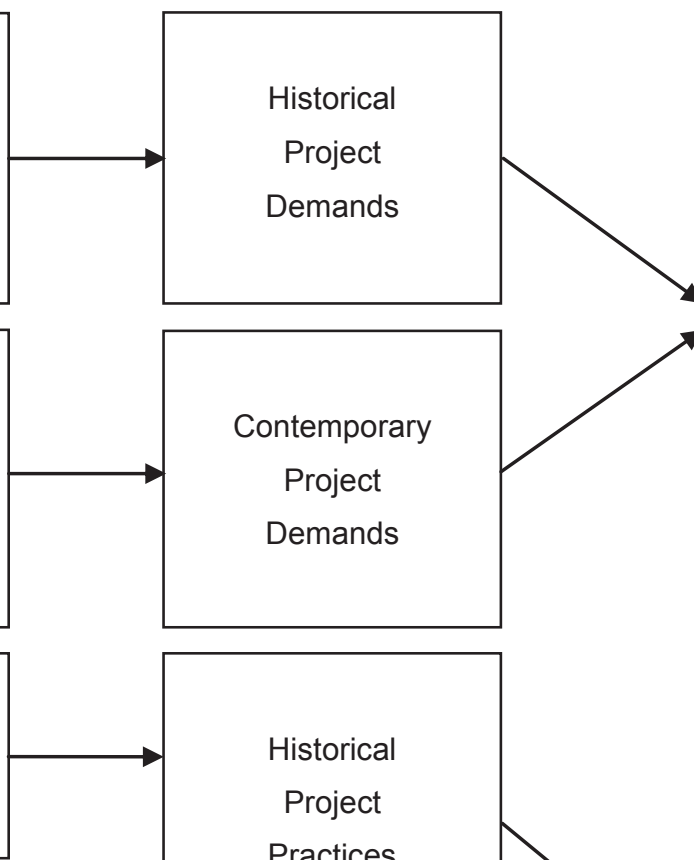

Historical

Project

Practices
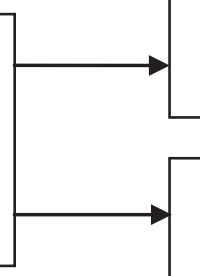

Contemporary

Project

Practices
Observed Changes

in

Project

Demands

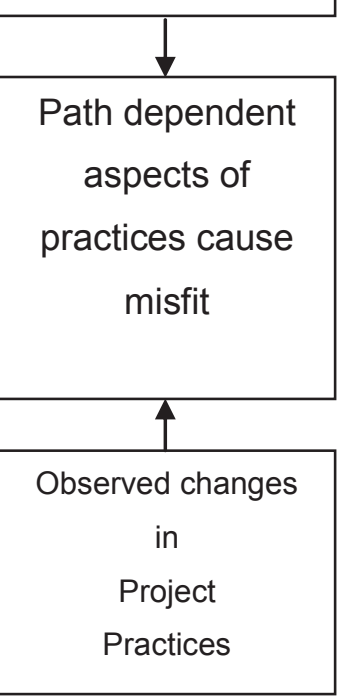

